\title{
High-Dose (8o Gy) Intensity-Modulated Radiation Therapy with Daily Image-Guidance as Primary Treat- ment for Localized Prostate Cancer
}

\author{
Pirus Ghadjar, Nicole Gwerder, Peter Manser, Jacqueline Vock, Axel Madlung, Roberto Mini, \\ Daniel M. Aebersold'
}

\begin{abstract}
Purpose: To report acute and late toxicity in prostate cancer patients treated by high-dose intensity-modulated radiation therapy (IMRT) with daily image-guidance.

Patients and Methods: From 06/2004-03/2008, 102 men were treated with 80 Gy IMRT with daily image-guidance. The risk groups were as follows: low, intermediate, and high risk in $21 \%, 27 \%$, and $52 \%$ of patients, respectively. Hormone therapy was given to $65 \%$ of patients. Toxicity was scored according to the CTC scale version 3.0 .

Results: Median age was 69 years and median follow-up was 39 months (range, 16-61 months). Acute and late grade 2 gastrointestinal (GI) toxicity occurred in $2 \%$ and $5 \%$ of patients, respectively, while acute and late grade $3 \mathrm{GI}$ toxicity was absent. Grade 2 and 3 pretreatment genitourinary (GU) morbidity (PGUM) were 15\% and 2\%, respectively. Acute grade 2 and 3 GU toxicity were $43 \%$ and $5 \%$ and late grade 2 and $3 \mathrm{GU}$ toxicity were $21 \%$ and $1 \%$, respectively. After multiple Cox regression analysis, PGUM was an independent predictor of decreased late $\geq$ grade $2 \mathrm{GU}$ toxicity-free survival (hazard ratio $=9.4(95 \%$ confidence interval: 4.1, 22.0), $\mathrm{p}<0.001)$. At the end of follow-up, the incidence of late grade 2 and $3 \mathrm{GU}$ toxicity decreased to $7 \%$ and $1 \%$, respectively.

Conclusion: GI toxicity rates after IMRT with daily image-guidance were excellent. GU toxicity rates were acceptable and strongly related to PGUM.
\end{abstract}

Key Words: High dose $\cdot$ IMRT · Daily image-guidance $\cdot$ Prostate cancer

Strahlenther Onkol 2010;186:687-92

DOI 10.1007/s00066-010-2180-8

\section{Intensitätsmodulierte Hochdosis-Radiotherapie (80 Gy) mit täglicher Image Guidance als Primärtherapie beim lokalisierten Prostatakarzinom}

Ziel: Beschreibung der Akut- und Spätnebenwirkungen bei Patienten mit Prostatakarzinom, die mit intensitätsmodulierter Hochdosis-Radiotherapie (IMRT) und täglicher Image Guidance behandelt wurden.

Patienten und Methodik: Von 06/2004 bis 03/2008 wurden 102 Männer mit 80 Gy IMRT behandelt. Die Zuordnung zu Risikogruppen ergab: niedrig bei $21 \%$, mittelhoch bei $27 \%$ und hoch bei $52 \%$ der Patienten. Hormontherapie erhielten $65 \%$ der Patienten. Die Toxizität wurde anhand der CTC Kriterien Version 3.0 bestimmt.

Ergebnisse: Das mediane Alter betrug 69 Jahre und die mediane Nachbeobachtungszeit war 39 Monate (Spannbreite, 16-61 Monate). Akute und späte Grad-2-gastrointestinale (GI) Nebenwirkungen traten in $2 \%$ und 5\% der Fälle auf; akute oder späte Grad-3-GI Nebenwirkungen wurden nicht beobachtet. Die Grad-2- und -3-urogenitale (GU) Morbidität, welche bereits vor IMRT bestand (PGUM), betrug 15\% und 2\%. Akute Grad-2- und -3-GU Nebenwirkungen lagen bei $43 \%$ und 5\% und späte Grad-2- und -3-GU Nebenwirkungen bei $21 \%$ und 1\%. In der multiplen Cox Regressionsanalyse erwies sich PGUM als unabhängiger Prädiktor für ein verkürztes (spät) $\geq$ Grad-2-GU nebenwirkungsfreies Überleben (hazard ratio $=9.4$ [95\% confidence interval: 4.1, 22.0], $p<0.001)$. Am Ende des Nachbeobachtungszeitraumes sank die Inzidenz von späten Grad-2 und -3-GU Nebenwirkungen auf $7 \%$ und $1 \%$.

Schlussfolgerung: Die GI Nebenwirkungsrate nach IMRT mit täglicher Image Guidance war exzellent. GU Nebenwirkungsraten waren akzeptabel und standen in engem Zusammenhang den urogenitalen Beschwerden vor Radiotherapie.

Schlüsselwörter: Hochdosis · IMRT · Tägliche Image Guidance · Prostatakarzinom

\footnotetext{
${ }^{1}$ Department of Radiation Oncology with Division of Medical Radiation Physics, Inselspital, Bern University Hospital, and University of Bern, Bern, Switzerland.
} 


\section{Introduction}

Significantly increased gastrointestinal (GI) toxicity was the major drawback of three-dimensional conformal radiotherapy (3D-CRT)-based dose-escalation in the treatment of prostate cancer (PCA) [1, 4, 9, 15, 22, 31]. The development of intensity-modulated radiation therapy (IMRT) allowed better preservation of the organs at risk and significantly decreased GI toxicity compared to 3D-CRT $[6,18,30]$. Thus, today IMRT is the gold-standard treatment for radiotherapy (RT) of PCA $[10,28]$. To account for the interfractional and intrafractional movement of the prostate [13, 21, 22, 29], image guidance was shown to be essential to avoid large safety margins around the clinical target volume (CTV). This report presents the pretreatment GI and genitourinary (GU) morbidity (PGUM) rates as well as acute and late GI/GU toxicity and early biochemical control data of 102 patients treated using high-dose IMRT with daily image-guidance.

\section{Patients and Methods}

Patient Selection and Characteristics

A total of 108 consecutive men with histologically proven PCA and $\mathrm{cN0}$ cM0 status were treated by IMRT with daily image guidance after obtaining informed consent in accordance with the standards of the local ethics committee. The pretreatment staging included a digital rectal examination, transrectal ultrasound (TRUS), biopsy with specification of the Gleason score, prostate-specific antigen (PSA), computed tomography (CT) and/or magnetic resonance imaging (MRI), a total-body bone scan, and was defined according to the 2002 American Joint Committee on Cancer tumor, lymph nodes, and metastasis system [27]. Risk of recurrence was assessed according to the National Comprehensive Cancer Network practice guidelines in oncology (www.nccn.org). A total of 6 patients were excluded from the study, 1 with a change in the treatment plan during the treatment, 1 because of interruption of the RT for 3 weeks, 1 with different dose constraints than described below and 3 patients because of death in the absence of PCA recurrence $<9$ months after RT (insufficient follow-up). The study population, thus, consisted of 102 patients, treated between 06/2004 and 03/2008. Patients were retrospectively analyzed. Median age of the patients was 69 years (range, 50-81 years), median follow-up was 39 months (range, 16-61 months). No patient was lost to follow-up, 87/102 (85\%) patients had a minimal follow-up of 24 months. The risk groups were as follows: low, intermediate, and high risk in 21 (21\%), 28 (27\%), and $53(52 \%)$ patients, respectively. A total of $24 / 102(24 \%)$ had undergone a transurethral resection of the prostate (TUR-P) a median of 42 months prior to IMRT (range, 1-199 months). In 9 of these patients, the time between TUR-P and IMRT was $<12$ months. The clinical characteristics of the patients are shown in Table 1.
Table 1. Patient characteristics. PSA: prostate-specific antigen, FU: follow-up, TUR-P: transurethral resection of the prostate. ${ }^{\text {a Median time }}$ between TUR-P and IMRT was 42 months (range, 1-199 months), in 9 patients the time interval was $<12$ months; ${ }^{b}$ period after completion of treatment.

Tabelle 1. Patientencharakteristika. PSA: Prostata-spezifisches Antigen, FU: follow-up, TUR-P: transurethrale Prostataresektion. ${ }^{\text {aDie }}$ mediane Zeit zwischen TUR-P und IMRT betrug 42 Monate (1-199 Monate), bei 9 Patienten war das Intervall <12 Monate; beitraum nach Abschluss der Behandlung.

\begin{tabular}{ll}
\hline Total patients & $\mathbf{n}=\mathbf{1 0 2}(\%)$ \\
\hline Age & \\
$\leq 69$ years & $52(51)$ \\
$\quad>69$ years & $50(49)$ \\
Tumor classification & \\
cT1 & $37(36)$ \\
cT2 & $21(21)$ \\
cT3a & $24(23)$ \\
cT3b & $18(18)$ \\
cT4 & $2(2)$ \\
Gleason score & \\
$2-6$ & $47(46)$ \\
7 & $43(42)$ \\
8-10 & $12(12)$ \\
Pre-treatment PSA & \\
$\leq 10$ ng/mL & $55(54)$ \\
$>10$ ng/mL & $47(46)$ \\
Risk group & \\
Low & $21(21)$ \\
Intermediate & $28(27)$ \\
High & $53(52)$ \\
Hormonal therapy & \\
no & $36(35)$ \\
yes & $66(65)$ \\
Prior TUR-Pa & \\
no & $78(76)$ \\
yes & $24(24)$ \\
Median FU months ${ }^{b}$ (range) & $39(16-61)$ \\
\hline &
\end{tabular}

Hormonal Therapy

A total of 66 patients $(65 \%)$ received concomitant and either neoadjuvant or adjuvant hormonal therapy (HT), with a median duration of 6 months (range, 1-34 months). Indications for HT were size reduction of the prostate, or intermediate or high-risk features. A total of 65 patients received combined androgen blockade consisting of antiandrogen and gonadotropin-releasing hormone analogue. One patient received antiandrogen monotherapy.

\section{External Beam Radiotherapy}

All patients were treated with 80 Gy IMRT in standard fractionation with daily image-guidance as previously described [8]. Briefly, prior to the treatment, three gold markers were implanted into the prostate of every patient under TRUS 
guidance. 94 of the 102 patients (92\%) underwent an MRI of the pelvis, and the digital data were used for image fusion with the planning CT. To estimate the risk for seminal vesicle (SV) invasion, the Roach formula [23] was calculated for each patient. If the risk for SV invasion was $>15 \%$, as it was the case in 59 patients, the proximal third of the SV was included in the CTV electively. If invasion of the base of the SV was seen in the MRI (cT3b) image, the whole SV were electively included in the CTV. The planning target volume (PTV) was then delineated by encompassing the prostate with $5 \mathrm{~mm}$ safety margins in all directions except dorsally, where a $3 \mathrm{~mm}$ margin was added. A set of dose constraints were used and localization of the prostate prior to every RT fraction (daily image-guidance) was performed as previously described [8, 29]. The duration of IMRT reached a median of 56 days (range, 52-63 days).

\section{Follow-Up Protocol}

Patients were seen by a radiation oncologist at least weekly during the RT. Follow-up visits were arranged 2-4 weeks after completion of IMRT and every 3-6 months for the first 2 years and annually thereafter with a digital rectal examination and a serum PSA level obtained at each visit. Patients alternated follow-up visits between their urologist and radiation oncologist.

\section{Toxicity Scoring and Biochemical Failure}

Pretreatment morbidity and acute and late toxicity were graded using the common terminology criteria for adverse events (CTC AE) version 3.0 (http://ctep.cancer.gov/forms/ CTCAEv3.pdf) from the National Cancer Institute as previously described [8].

Biochemical no evidence of disease (bNED) was assessed according to the Phoenix criteria, defining a biochemical failure as a PSA rise of $2 \mathrm{ng} / \mathrm{ml}$ or more above the nadir PSA [24].

\section{Statistical Analysis}

Descriptives included absolute and relative frequencies for categorical variables, median and range for quantitative variables. The primary objective was the occurrence of acute and late $\geq$ grade $2 \mathrm{GI}$ and GU toxicity. For statistical analysis, age ( $\leq$ vs. $>69$ years), PTV size $\left(\leq\right.$ vs. $\left.>94 \mathrm{~cm}^{3}\right)$, PTVD $_{\max }(\leq 83.9$ Gy vs. $>83.9 \mathrm{~Gy})$, rectal $\mathrm{V}_{75}(\leq 4 \%$ vs. $>4 \%)$ and rectal $\mathrm{V}_{47}$ $(\leq 17 \%$ vs. $>17 \%)$ were grouped according to the median. PGUM (grade 0-1 vs. grade 2-3), acute and late GI toxicity (grade 0 vs. grade $1-2$ ), and acute and late GU toxicity (grade $0-1$ vs. grade 2-3) were grouped. Categorical variables were compared using Fisher's exact test. Estimation of actuarial rates were calculated using the Kaplan-Meier product limit methodology and compared using the log-rank test [11]. Univariate Cox regression and a multiple Cox regression model with forward and backward selection was used to determine independent prognostic factors for decreased late
Table 2. Pre-treatment gastrointestinal morbidity and gastrointestinal acute and late toxicity. Pre-Tx: pre-treatment; athe highest toxicity in a patient was counted as a single event; ${ }^{b}$ during therapy and until 3 months after completion; ${ }^{\mathrm{C}}$ maximal late toxicity $>3$ months after completion of therapy; ${ }^{d}$ incidence of late toxicity at last follow-up visit. There was no grade $\geq$ grade $3 \mathrm{Gl}$ toxicity observed.

Tabelle 2. Gastrointestinale Morbidität vor Behandlung und akut und spät gastrointestinale Nebenwirkungen. Pre-Tx: vor Behandlung;. ${ }^{a}$ die maximal erreichte Toxizitäts eines Patienten wurde als 1 Ereignis gewertet; ${ }^{b}$ während und bis 3 Monate nach Abschluss der Behandlung; c maximale Spättoxizität >3 Monate nach Abschluss der Behandlung; dInzidenz von Spättoxizität beim letzten Nachuntersuchungstermin ( $\geq$ Grad-3-Gl Toxizität wurde nicht beobachtet).

\begin{tabular}{|c|c|c|c|c|c|}
\hline & & Pre-Tx & Acute $^{\mathrm{b}}$ & Late $^{c}$ & Last late $^{\mathrm{d}}$ \\
\hline Toxicity & Grade & n (\%) & n (\%) & n (\%) & n (\%) \\
\hline \multirow[t]{3}{*}{ Diarrhea } & 0 & $102(100)$ & $75(74)$ & $95(93)$ & $102(100)$ \\
\hline & 1 & 0 & $25(24)$ & $7(7)$ & 0 \\
\hline & 2 & 0 & $2(2)$ & 0 & 0 \\
\hline \multirow[t]{3}{*}{ Rectal pain } & 0 & $101(99)$ & $94(87)$ & $98(96)$ & $100(98)$ \\
\hline & 1 & $1(1)$ & $8(13)$ & $2(2)$ & $2(2)$ \\
\hline & 2 & 0 & 0 & $2(2)$ & 0 \\
\hline \multirow[t]{3}{*}{ Rectal bleeding } & 0 & $99(97)$ & $95(93)$ & $73(72)$ & $85(83)$ \\
\hline & 1 & $3(3)$ & $7(7)$ & $26(25)$ & $17(17)$ \\
\hline & 2 & 0 & 0 & $3(3)$ & 0 \\
\hline \multirow[t]{3}{*}{ Highest GI ${ }^{\mathrm{a}}$} & 0 & $99(97)$ & $65(64)$ & $66(65)$ & $83(81)$ \\
\hline & 1 & $3(3)$ & $35(34)$ & $31(30)$ & $19(19)$ \\
\hline & 2 & 0 & $2(2)$ & $5(5)$ & 0 \\
\hline
\end{tabular}

$\geq$ grade 2 GU toxicity-free survival [3]. Variables were included in the model if the univariate $p$ value was $<0.1$. Statistical significance was considered on a 2-sided level of $\alpha=0.05$. Statistical analysis was performed with SPSS version 16.0 (SPSS Inc., Chicago, IL).

\section{Results}

\section{Acute and Late Gastrointestinal Toxicity}

Acute grade 1 GI toxicity was experienced in 35 patients (34\%), while grade 2 toxicity was observed in 2 patients $(2 \%)$ with diarrhea being the most commonly observed symptom. Acute grade 3 GI toxicity was absent (Table 2).

Late grade 1 and 2 GI toxicity occurred in 31 (30\%) and 5 (5\%) patients, respectively, and rectal bleeding was the most commonly observed symptom. Late grade 3 GI toxicity was absent. No patient reported experiencing fecal incontinence. The median time from the completion of IMRT to the occurrence of late $\geq$ grade 2 GI toxicity was 25 months (range, 12-41 months). The actuarial likelihood at 5 years for the development of late $\geq$ grade 2 GI toxicity was $7 \%$. The incidence of late GI toxicity decreased as time from treatment elapsed. At the last follow-up visit, late grade 1 toxicity was present in 19 (19\%) patients, and no patient suffered of late grade 2 GI 
toxicity anymore at that time. Acute and late GI toxicity was not associated with any DVH parameter tested.

\section{Acute and Late Genitourinary Toxicity}

Prior to treatment, 15 patients $(15 \%)$ had grade 2 and 2 patients $(2 \%)$ suffered of grade 3 PGUM (Table 3$)$. The most commonly observed PGUM symptoms were increased frequency/urgency and retention. PGUM was not associated with a history of prior TUR-P $(\mathrm{p}=1.0)$. After treatment acute grade 2 and 3 GU toxicity occurred in $44(43 \%)$ and $5(5 \%)$ patients, respectively. Acute $\geq$ grade 2 GU toxicity was significantly more common in patients who already suffered of PGUM ( $\mathrm{p}<0.001)$. Interestingly, acute toxicity was decreased in patients with history of TUR-P $(n=24, p=0.039)$; however, if only patients with TUR-P $<12$ months prior to IMRT were analyzed $(n=9)$, acute GU toxicity was not significantly different $(\mathrm{p}=0.50)$. Acute GU symptoms were often ameliorated with $\alpha$-blockers or anti-inflammatory medications. Late grade 2 and $3 \mathrm{GU}$ toxicity occurred in $21(21 \%)$ and $1(1 \%)$ of patients, respectively. There was no acute or late grade 4 GU toxicity. The median time from the completion of IMRT to the occurrence of late $\geq$ grade 2 GU toxicity was 34 months (range, 4-61 months). The actuarial incidence of late $\geq$ grade 2 GU toxicity was $27 \%$ at 5 years. Late $\geq$ grade 2 GU toxicityfree survival was significantly associated with the presence of PGUM ( $<<0.001)$ (Figure 1), presence of TUR-P $<12$ months prior to IMRT $(\mathrm{p}=0.003)$, presence of acute GU toxicity $(\mathrm{p}=$ $0.01)$, older age $(\mathrm{p}=0.03)$ but not with HT $(\mathrm{p}=0.66)$, PTV size $(\mathrm{p}=0.76)$, or PTVD $\mathrm{D}_{\max }(\mathrm{p}=0.2)$. After multiple Cox regression

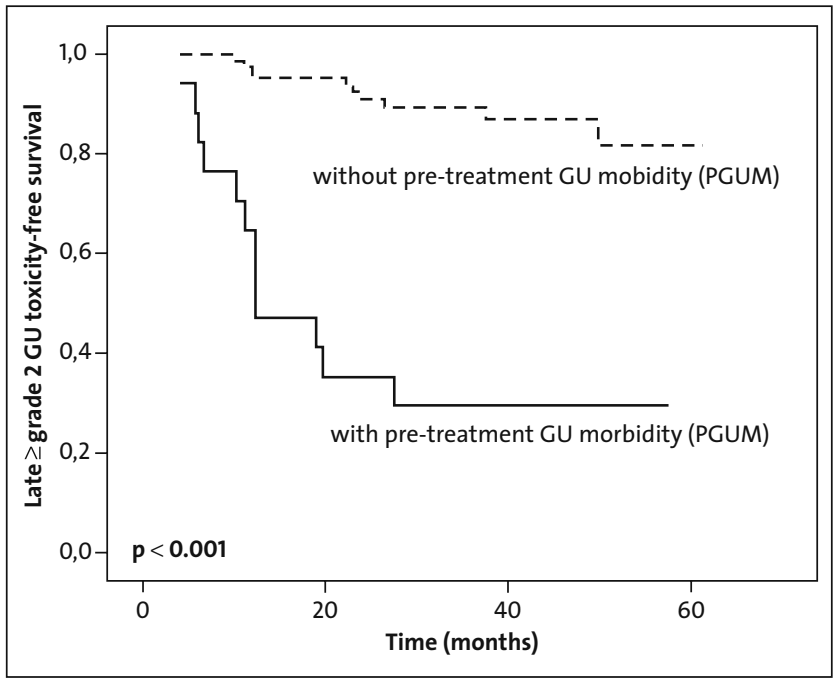

Figure 1. Actuarial analysis of 3 -year late $\geq$ grade $2 \mathrm{GU}$ toxicity-free survival stratified by the presence of pretreatment genitourinary morbidity (PGUM).

Abbildung 1. Kaplan-Meier-Analyse des spät ( $\geq$ Grad 2) urogenital nebenwirkungsfreien Überlebens nach 3 Jahren, stratifiziert nach Vorhandensein von urogenitaler Morbidität vor Behandlung (PGUM).
Table 3. Pre-treatment genitourinary morbidity and genitourinary acute and late toxicity. Pre-Tx: pre-treatment; ${ }^{a}$ the highest toxicity in a patient was counted as a single event; ${ }^{b}$ during therapy and until 3 months after completion; ${ }^{c}$ maximal late toxicity $>3$ months after completion of therapy; dincidence of late toxicity at last follow-up visit. There was no grade $\geq$ grade $4 \mathrm{GU}$ toxicity observed.

Tabelle 3. Urogenitale Morbidität vor Behandlung und akut und spät urogenitale Nebenwirkungen. Pre-Tx: vor Behandlung; adie maximal erreichte Toxizitäts eines Patienten wurde als 1 Ereignis gewertet; ${ }^{b}$ während und bis 3 Monate nach Abschluss der Behandlung; ' ${ }^{\text {maxi- }}$ male Spättoxizität >3 Monate nach Abschluss der Behandlung; ${ }^{\mathrm{d}} \mathrm{In}-$ zidenz von Spättoxizität beim letzten Nachuntersuchungstermin ( $\geq$ Grad-4-GU Toxizität wurde nicht beobachtet).

\begin{tabular}{|c|c|c|c|c|c|}
\hline & & Pre-Tx & Acute $^{b}$ & Late $^{c}$ & Last late $^{\mathrm{d}}$ \\
\hline Toxicity & Grade & n (\%) & n (\%) & n (\%) & n (\%) \\
\hline \multirow[t]{4}{*}{ Dysuria } & 0 & $95(93)$ & $63(62)$ & $93(91)$ & $98(96)$ \\
\hline & 1 & $7(7)$ & $30(30)$ & $8(8)$ & $4(4)$ \\
\hline & 2 & 0 & $7(7)$ & $1(1)$ & 0 \\
\hline & 3 & 0 & $2(2)$ & 0 & 0 \\
\hline \multirow[t]{3}{*}{ Incontinence } & 0 & $94(92)$ & $92(90)$ & $88(86)$ & $92(90)$ \\
\hline & 1 & $7(7)$ & $9(9)$ & $12(12)$ & $9(9)$ \\
\hline & 2 & $1(1)$ & $1(1)$ & $2(2)$ & $1(1)$ \\
\hline \multirow[t]{4}{*}{ Retention } & 0 & $57(56)$ & $52(51)$ & $71(70)$ & $91(89)$ \\
\hline & 1 & $38(37)$ & $25(25)$ & $25(24)$ & $10(10)$ \\
\hline & 2 & $6(6)$ & $23(22)$ & $5(5)$ & 0 \\
\hline & 3 & $1(1)$ & $2(2)$ & $1(1)$ & $1(1)$ \\
\hline \multirow[t]{4}{*}{$\begin{array}{l}\text { Frequency/ur- } \\
\text { gency }\end{array}$} & 0 & $65(64)$ & $23(23)$ & $51(50)$ & $71(70)$ \\
\hline & 1 & $28(27)$ & $46(45)$ & $34(33)$ & $24(23)$ \\
\hline & 2 & $8(8)$ & $30(29)$ & $17(17)$ & $7(7)$ \\
\hline & 3 & $1(1)$ & $3(3)$ & 0 & 0 \\
\hline \multirow[t]{3}{*}{ Hematuria } & 0 & $102(100)$ & $102(100)$ & $93(91)$ & $99(97)$ \\
\hline & 1 & 0 & 0 & $7(7)$ & $3(3)$ \\
\hline & 2 & 0 & 0 & $2(2)$ & 0 \\
\hline \multirow[t]{4}{*}{ Highest GUa } & 0 & $39(38)$ & $11(11)$ & $37(36)$ & $59(58)$ \\
\hline & 1 & $46(45)$ & $42(41)$ & $43(42)$ & $35(34)$ \\
\hline & 2 & $15(15)$ & $44(43)$ & $21(21)$ & $7(7)$ \\
\hline & 3 & $2(2)$ & $5(5)$ & $1(1)$ & $1(1)$ \\
\hline
\end{tabular}

analysis with forward and backward selection, PGUM was an independent positive predictor of late $\geq$ grade 2 GU toxicityfree survival (hazard ratio $=9.4$ (95\% confidence interval: 4.1 , $22.0), \mathrm{p}<0.001)($ Table 4$)$. When all patients with a history of TUR-P were analyzed $(n=24)$, late $\geq$ grade 2 GU toxicity-free survival was not significantly decreased $(p=0.32)$. Interestingly, late GU toxicity decreased as time from treatment elapsed. At last follow-up visit, only 7 (7\%) or $1(1 \%)$ still complained of late grade 2 or $3 \mathrm{GU}$ toxicity, respectively, being less than 
Table 4. Univariate and multiple Cox regression analysis of factors associated with late $\geq$ grade 2 genitourinary toxicity-free survival. RR: relative risk, $\mathrm{Cl}$ : $95 \%$ RR confidence intervals, TUR-P: transurethral resection of the prostate, IMRT: intensity modulated radiation therapy, PGUM: pre-treatment genitourinary morbidity.

Tabelle 4. Univariate und multiple Cox Regressionsanalyse von Faktoren welche mit spät- $\geq$ Grad-2-urogenital nebenwirkungsfreiem Überleben assoziiert sind. RR: relatives Risiko, Cl: 95\% RR Konfidenzintervalle, TUR-P: transurethrale Prostataresektion, IMRT: Intensitätsmodulierte Radiotherapie, PGUM: urogenitale Morbidität vor Behandlungsbeginn.

\begin{tabular}{llll}
\hline Factor & RR & CI & p \\
\hline Univariate Cox regression: & & & \\
PTV size $>94 \mathrm{~cm}^{3}$ vs. $\leq 94 \mathrm{~cm}^{3}$ & 1.1 & $0.5-2.6$ & 0.763 \\
PTV D $_{\max }>83.9$ Gy vs. $\leq 83.9 \mathrm{~Gy}$ & 1.7 & $0.7-4.1$ & 0.208 \\
Age $>69$ years vs. $\leq 69$ years & 2.5 & $1.0-6.2$ & 0.042 \\
TUR-P $<12$ months prior to IMRT & 4.0 & $1.5-11.2$ & 0.007 \\
$\quad \begin{array}{l}\text { Acute grade 2-3 toxicity versus } \\
\text { grade 0-1 }\end{array}$ & 3.0 & $1.2-7.8$ & 0.020 \\
$\quad$ PGUM grade 2-3 vs. grade 0-1 & 9.4 & $4.1-22.0$ & $<0.001$ \\
& & & \\
Multiple Cox regression: & & & \\
$\quad$ PGUM grade 2-3 vs. grade 0-1 & 9.4 & $4.1-22.0$ & $<0.001$ \\
\hline
\end{tabular}

half of the patients who suffered of grade 2 or 3 PGUM prior to treatment.

\section{Biochemical Control}

With a median follow-up of 39 months, it is too early to report sound biochemical control rates, especially taking into account that $65 \%$ of the patients underwent HT. However, after IMRT, $92 \%(61 / 66)$ of patients with and $50 \%(18 / 36)$ of patients without HT reached a PSA nadir value $\leq 0.5 \mathrm{ng} / \mathrm{mL}$. During follow-up, 12 patients (12\%) experienced biochemical relapse, all of whom belonged to the high-risk of recurrence group. The actuarial 5-year biochemical relapse-free survival was $100 \%, 100 \%$, and $68 \%$ for low-, intermediate- and highrisk patients, respectively $(\mathrm{p}=0.003)$.

\section{Discussion}

Radical prostatectomy combined with pelvic lymphadenectomy is known to produce comparable tumor control rates compared to conventional dose 3D-CRT in localized PCA $[5,16]$, and introduction of nerve-sparing operation technique could significantly reduce the risk of associated severe stress incontinence [14]. Thus, modern RT is required to achieve low toxicity rates and high long-term effectiveness to be recommended as a therapeutic alternative to radical prostatectomy.

After a median follow-up of 39 months, our results after high-dose IMRT daily image-guidance are encouraging with respect to observed treatment-related toxicity. Acute and late grade 3 GI toxicity was absent, while acute and late grade 2 GI toxicity was observed in $2 \%$ and $5 \%$ of the patients, respectively.

Concerning GU toxicity, notably, our patients suffered of a significant PGUM, being of grade 2 and 3 in $15 \%$ and $2 \%$, respectively, of the patients prior to IMRT. Acute grade 2 and $3 \mathrm{GU}$ toxicity occurred in $43 \%$ and $5 \%$ and late grade 2 and 3 GU toxicity was observed in $21 \%$ and $1 \%$, respectively.

Our acute toxicity rates compare favorably with those reported for 111 patients treated with IMRT 78 Gy within a prospective randomized trial, where the acute grade 2 and 3 GI toxicity was $41 \%$ and $8 \%$ and the acute grade 2 and $3 \mathrm{GU}$ toxicity was $21 \%$ and $2 \%$ (CTC score), respectively [19].

Others have reported the toxicity profile (CTC score) after ultrahigh-dose IMRT with 86.4 Gy after a median follow-up of 53 months and acute grade 2 GI toxicity was $8 \%$, acute grade 2 and 3 GU $22 \%$ and $1 \%$, respectively, actuarial late $\geq$ grade 2 GI toxicity at 5 years was $4 \%$ and actuarial late $\geq$ grade 2 GU toxicity was $16 \%$ at 5 years [2]. Compared to this study, our GI rates seem comparably low; however, GU toxicity rates were higher in our patients despite the use of a lower total dose in our patients ( $80 \mathrm{~Gy}$ vs. $86.4 \mathrm{~Gy}$ ). Importantly, one has to consider that in our treatment plans the dose coverage of the PTV was defined more strictly, thus, aiming to set the $\mathrm{V}_{95}$ to $>99 \%$ (volume of the PTV receiving at least $95 \%$ of the prescribed dose > 99\%) [8]; however, the treatment plan criteria for $81 \mathrm{~Gy}$ or $86.4 \mathrm{~Gy}$ plans were $\mathrm{V}_{95}>90 \%$ or $\mathrm{V}_{95}>85 \%$, respectively [18], moreover for $81 \mathrm{~Gy}$ and $86.4 \mathrm{~Gy}$, a lower single fraction dose $(1.8 \mathrm{~Gy})$ was used.

In this study, a significant association between acute GI/ GU toxicity and decreased late GI/GU toxicity-free survival could be demonstrated. This is in accordance with the findings of others [12, 26, 30]. In addition, we could also describe not only the PGUM rate of our patients and its significant association with acute GU toxicity, but also its role as an independent positive predictor for decreased late GU toxicity-free survival. A relative large proportion of our patients (24\%) had undergone TUR-P at different times prior to IMRT. We found that a history of TUR-P $<12$ months before IMRT was associated with decreased late $\geq$ grade 2 GU toxicity-free survival. An association between previous TUR-P and GU toxicity has been previously described [20].

In our patients, HT did not influence the incidence of late GI or GU toxicity. A large meta-analysis [17] recently demonstrated that addition of short-term HT significantly decreased GI and GU late toxicities.

Late toxicity after RT is known to increase over time. However, during follow-up of our series of patients, the incidence of late GI and especially of late GU toxicity were decreasing. At the last follow-up visit, late GU toxicity rates dropped below half of the observed PGUM rates. A similar report was recently made by others [7], who showed that patients presenting with obstructive urinary symptoms experienced a clear symptom relieve after IMRT \pm HT. Generally, the grade $2 \mathrm{GU}$ toxicities observed in our patients consisted of increased 
frequency/urgency or retention and were often significantly improved after $\alpha$-blocker or anti-inflammatory medications. These drugs were received by most of the symptomatic patients during IMRT and during follow-up; thus, this drug therapy at least contributed to the observed decrease of late GU toxicity during time.

The follow-up of less than 5 years is too short to provide sound biochemical control data. However, all observed events of biochemical relapse $(12 \%)$ occurred in patients with highrisk features and our actuarial 5-year biochemical relapsefree survival rates of $100 \%, 100 \%$, and $68 \%$ are comparable with the 5-year rates of $98 \%, 85 \%$, and $70 \%$ described after ultrahigh-dose IMRT for low-, intermediate-, and high-risk patients, respectively [2].

We are aware of the obvious limitations of our study, being the retrospective nature of the study and limited followup. Nevertheless, this report provides strong evidence for the low toxicity profile of high-dose IMRT. In the decision making for appropriate local treatment of PCA, the patient should not be informed about "RT" but should be informed about "modern RT" and its associated low treatment-related acute and late toxicity.

\section{References}

1. Al-Mamgani A, van Putten WL, Heemsbergen WD, et al. Update of Dutch multi center dose-escalation trial of radiotherapy for localized prostate cancer. Int J Radiat Oncol Biol Phys 2008;72:980-8.

2. Cahlon 0, Zelefsky MJ, Shippy A, et al. Ultra-high dose (86.4 Gy) IMRT for localized prostate cancer: toxicity and biochemical outcomes. Int J Radiat Oncol Biol Phys 2008;71:330-7.

3. Cox DR, Oakes D. Analysis of survival data. London, United Kingdom: Chapman and Hall, 1984;110-20.

4. Dearnaley DP, Sydes MR, Graham JD, et al. Escalated-dose versus standarddose conformal radiotherapy in prostate cancer: first results from the MRC RT01 randomised controlled trial. Lancet Oncol 2007;8:475-87.

5. D'Amico AV, Whittington R, Malkowitcz SB, et al. Biochemical outcome after radical prostatectomy external beam radiation therapy, or interstitial radiation therapy for clinically localized prostate cancer. JAMA 1998;280: $969-74$.

6. Dolezel M, Odrazka K, Vaculikova M, et al. Dose escalation in prostate radiotherapy up to $82 \mathrm{~Gy}$ using simultaneous integrated boost. Strahlenther Onkol 2009;186:197-202.

7. Fonteyne $\mathrm{V}$, Villeirs $\mathrm{G}$, Lumen $\mathrm{N}$, et al. Urinary toxicity after high dose intensity modulated radiotherapy as primary therapy for prostate cancer. Radiother Oncol 2009;92:42-7.

8. Ghadjar P, Vock J, Vetterli D et al. Acute and late toxicity in prostate cancer patients treated by dose escalated intensity modulated radiation therapy and organ tracking. Radiat Oncol 2008;3:35.

9. Goldner G, Dimopoulos J, Kirisits C, et al. Moderate dose escalation in threedimensional conformal localized prostate cancer radiotherapy. Strahlenther Onkol 2009;7:438-45.

10. Guckenberger M, Flentje M. Intensity-modulated radiotherapy (IMRT) of localized prostate cancer: a review and future perspectives. Strahlenther Onkol 2007;183:57-62.

11. Harris EK, Albert A. Survivorship analysis for clinical studies. New York, NY: Marcel Dekker, 1991;5-125.

12. Heemsbergen WD, Peeters STH, Koper PCM, et al. Acute and late gastrointestinal toxicity after radiotherapy in prostate cancer patients: consequential late damage. Int J Radiat Oncol Biol Phys 2006;66:3-10.

13. Kalz J, Sterzing F, Schubert K, et al. Dosimetric comparison of image guidance by megavoltage computed tomography versus bone alignment for prostate cancer radiotherapy. Strahlenther Onkol 2009;185:241-7.
14. Kessler TM, Burkhard FC, Studer UE. Nerve-sparing open radical retropubic prostatectomy. Eur Urol 2007;51:90-7.

15. Kuban DA, Tucker SL, Dong L, et al. Long-term results of of the M.D. Anderson randomized dose-escalation trial for prostate cancer. Int J Radiat Oncol Biol Phys 2008;70:67-74.

16. Kupelian PA, Elshaikh M, Reddy CA, et al. Comparison of the efficacy of local therapies for localized prostate cancer in the prostate-specific antigen era: a large single-institution experience with radical prostatectomy and external-beam radiotherapy. J Clin Oncol 2002;20:3376-85.

17. Lawton CA, Bae K, Pilepich M, et al. Long-term treatment sequelae after external beam irradiation with or without hormonal manipulation for adenocarcinoma of the prostate: Analysis of Radiation Therapy Oncology Group studies 85-31, 86-10, and 92-02. Int J Radiat Oncol Biol Phys 2008;70:437-41.

18. Leibel SA, Fuks Z, Zelefsky MJ, et al. Technological advances in externalbeam radiation therapy for the treatment of localized prostate cancer. Semin Radiat Oncol 2003;30:596-615.

19. Matzinger 0 , Duclos F, van den Bergh A, et al. Acute toxicity of curative radiotherapy for intermediate- and high-risk localised prostate cancer in the EORTC trial 22991. Eur J Cancer 2009;45:2825-34.

20. Peeters ST, Heemsbergen WD, van Putten WL, et al. Acute and late complications after radiotherapy for prostate cancer: results of a multicenter randomized trial comparing 68 Gy to $78 \mathrm{~Gy}$. Int J Radiat Oncol Biol Phys 2005;61:1019-34.

21. Pinkawa $M$, Pursch-Lee $M$, Asadpour $B$, et al. Image-guided radiotherapy for prostate cancer. Strahlenther Onkol 2008;12:679-85.

22. Polat B, Guenther I, Wilbert J. Intra-fractional uncertainties in image-guided intensity-modulated radiotherapy (IMRT) of prostate cancer. Strahlenther Onkol 2008;184:668-73.

23. Roach $3^{\text {rd }}$ M. Re: The use of prostate specific antigen, clinical stage and Gleason score to predict pathological stage in men with localized prostate cancer. J Urol 1993;150:1923-4.

24. Roach $3^{\text {rd }} M$, Hanks G, Thames Jr. H, et al. Defining biochemical failure following radiotherapy with or without hormonal therapy in men with clinically localized prostate cancer: recommendations of the RTOG-ASTRO Phoenix consensus conference. Int J Radiat Oncol Biol Phys 2006;65:965-74.

25. Sathya JR, Davis IR, Julian JA, et al. Randomized trial comparing iridium implant plus external-beam radiation therapy with external-beam radiation therapy alone in node-negative locally advanced cancer of the prostate. J Clin Oncol 2005;23:1192-9.

26. Schultheiss TE, Hanks GE, Hunt MA, et al. Incidence of and factors related to late complications in conformal and conventional radiation treatment of cancer of the prostate. Int J Radiat Oncol Biol Phys 2002;54:442-9.

27. Sobin $\mathrm{LH}$, Wittekind $\mathrm{CH}$. The prostate. In: TNM classification of malignant tumors. New York: Wiley-Liss, 2002;184-7.

28. Treutwein M, Hipp M, Kölbl 0, et al. IMRT of prostate cancer. Strahlenther Onkol 2009;185:379-83.

29. Vetterli D, Thalmann S, Behrensmeier Fet al. Daily organ tracking in intensity-modulated radiotherapy of prostate cancer using an electronic portal imaging device with a dose saving acquisition mode. Radiother Oncol 2006;79:101-8.

30. Zelefsky MJ, Levin EJ, Hunt M, et al. Incidence of late rectal and urinary toxicities after three-dimensional conformal radiotherapy and intensitymodulated radiotherapy for localized prostate cancer. Int J Radiat Oncol Biol Phys 2008;70:1124-9.

31. Zietman Al, DeSilvio ML, Slater JD, et al. Comparison of conventional-dose vs high-dose conformal radiation therapy in clinically localized adenocarcinoma of the prostate: a randomized controlled trial. JAMA 2005;294:1233-9.

\author{
Address for Correspondence \\ Prof. Dr. med. Daniel M. Aebersold \\ University of Bern - Inselspital \\ Department of Radiation Oncology \\ Freiburgstr. \\ 3011 Bern \\ Switzerland \\ Phone (+41) 31 632-2431, Fax -2342 \\ e-mail:daniel.aebersold@insel.ch
}

